\title{
A tether system for cardiovascular studies with the behaving micropig
}

\author{
D. E. ANDERSON \\ National Institute on Aging, Baltimore, Maryland \\ M. D. CROWELL \\ Johns Hopkins University School of Medicine, Baltimore, Maryland \\ and \\ A. W. FRENCH \\ National Institute on Aging, Baltimore, Maryland
}

\begin{abstract}
A tether system has been developed for continuous monitoring of blood pressure in the micropig. The micropig is a suitable model for blood-pressure research because of the similarity of its cardiovascular system to that of humans and because of its sensitivity to high sodium intake. The system consists of a metal boom, attached via a universal joint to a wall $6 \mathrm{ft}$ above floor level, that extends horizontally to the center of the enclosure. A fluid and electronic swivel affixed to the boom is connected to a flexible, hollow, metal tether that descends to a vest worn by the micropig. The vest contains a pressure transducer to which an indwelling arterial catheter is connected via a stopcock. The transducer cable and an infusion line ascend through the interior of the tether to the swivel. The system remains in equilibrium through a system of pulleys and counterweights. Continuous, 24-h recording shows a diurnal variation characterized by higher heart rate but lower blood pressure during the day than at night. The system has been found to be effective for continuous studies over intervals of a month or more.
\end{abstract}

Micropigs offer a number of advantages over dogs in behavioral research on blood-pressure regulation. Dogs have a high resistance to sodium-induced hypertension, but the pig is more susceptible to the development of experimental hypertension in response to high dietarysodium intake (Corbett, Kuller, Blaine, \& Damico, 1979). In addition, pigs appear to be more vulnerable to other extrinsic influences on long-term blood pressure, such as disruption of feeding schedules (Smith, Smith, \& Mameesh, 1964) or decreased space allowance (Barnett \& Hemsworth, 1986). The structure of their cardiovascular system is more similar to that of man than is the dog's (Hughes, 1986; Mitchell \& Bohr, 1984). They are less excitable in the presence of humans and become readily accustomed to human handling. Anatomical differences, including conformation of neck and legs, also render them easily maintained in vests and unlikely to reach monitoring apparatus.

Previous studies of blood pressure in the micropig have relied on discrete measurements from forcibly restrained animals (e.g., Cimini \& Zambraski, 1985). Technologies have been developed and refined for continuous, 24-h monitoring of arterial pressure and other variables in other tethered animals such as the dog (Kearns, Better, Daley,

Correspondence may be addressed to David E. Anderson, Laboratory of Behavioral Sciences, National Institute on Aging, Gerontology Research Center, 4940 Eastern Avenue, Baltimore, MD 21224.
\& Anderson, 1981). Our report describes the adaptation of this technology to continuous monitoring of arterial pressure in the partially free ranging micropig. This system enables studies of cardiovascular activity within the context of ongoing behavioral interactions with concurrent opportunity for remote and automatic infusion of nutrients or other substances, or timed withdrawal of blood samples, without the complications posed by the presence of humans in the immediate environment.

\section{CONSTRUCTION}

The tether system is comprised of three interconnected parts: (1) a one-piece vest worn by the subject, (2) a flexible, hollow, metal tether, and (3) a fluid and electronic swivel attached to a boom. The assembled system is shown in Figure 1.

The vest is made from a lightweight mesh fabric (28 in. long with a 10-in. circumference for a 35-lb micropig) that contains two reinforced legholes (4-5 in. in diameter) and $a$ third hole on the dorsal surface where an indwelling catheter can attach to a pressure transducer located in a shield. Installation of the pig in the vest requires insertion of the legs through the legholes, wrapping the vest around the anterior torso, and connecting a series of snaps at the anterior and posterior ends of the vest that anchor the Velcro overlap. The snap settings can be readjusted to accommodate growth of the animal during the study period. During monitoring periods, the vest is connected 


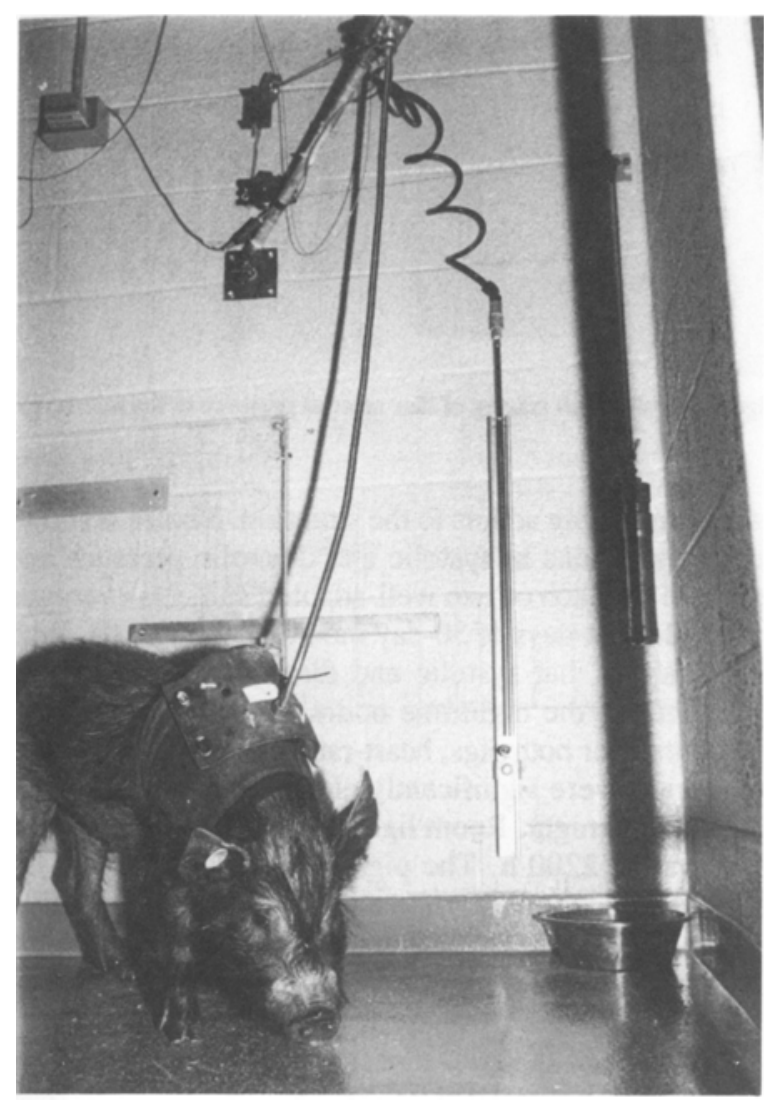

Figure 1. Photograph of a micropig wearing the leather vest and connected to the tether and boom assembly. The boom is approximately $6 \mathrm{ft}$ above foor level and is counterbalanced to minimize weight on the pig's back.

with snaps to a leather shield at the terminus of the tether cable.

The 5-ft-long tether is constructed of flexible stainless steel tubing with an outer diameter of $.365 \mathrm{in}$. and an inner diameter of 0.280 in. (Anaconda). A brass flange (2.5 in. in diameter) has a 0.365 -in. hole drilled in the center into which one end of the steel tube is soldered, providing an anchor for the $6 \times 6$ in. leather shield. The shield's eight mating snaps are arranged to elevate the center front area of the shield approximately $1.5 \mathrm{in}$. when attached to the vest, providing a protected space for the pressure transducer (Statham Model P10) and the connected three-way stopcock, which are affixed to the shield. The stopcock connects to both the indwelling catheter and an infusion line. Catheter patency is maintained via a remotely located peristaltic pump (Harvard Model 607), which provides for slow infusion of lightly heparinized saline ( 7 USP units $/ \mathrm{ml}$ at a rate of $150 \mathrm{ml} /$ day) into the arterial system. This arrangement permits ready access to the monitoring apparatus without removal of the vest. With experience, the pig learns to lie quietly during experimenter interaction with the system.

Wires from the pressure transducer pass through the interior of the tether and are soldered to an electronic con- nector (Cannon Model MS3101A145-5S). The connections are covered with silicone glue to prevent corrosion or breakage. An electronic swivel (BRS Model CAY-960$6)$ is mounted vertically on a right-angle bracket $(0.25$-in. mild steel) attached to the metal boom (Figure 2). A ballbearing brace that supports the weight of the system is made by press fitting a ball bearing (Delco Model 77038) into a $1.4 \times 1.4 \times 0.35$ in. thick block of aluminum. A 0.320 -in.-diameter hole is drilled through the aluminum block so that the central core of the ball bearing is accessible to both sides of the block of aluminum. Four 0.156 in.-diameter holes are drilled through the corners of the block, permitting the finished ball-bearing assembly to be fastened later to the swivel mounting screws. A stainless steel tube measuring $1.5 \times 0.305 \mathrm{in}$. (outer diameter) and 0.250 in. (inner diameter) is slotted lengthwise to within 0.375 in. of either end. The slot's width should not exceed 0.625 in. One end of the tubing is then flared, and the other end is passed through the ball bearing with the aid of a vise. The wires from the swivel pass through the upper, flared end of the stainless steel tubing to the nonflared end, and the saline infusion line passes through the 0.625 -in. slot. The bearing assembly is fitted below the swivel unit (Figure 2), with the swivel's central shaft centered in the stainless steel tubing. The swivel wires exiting through the bottom of the stainless steel tubing are

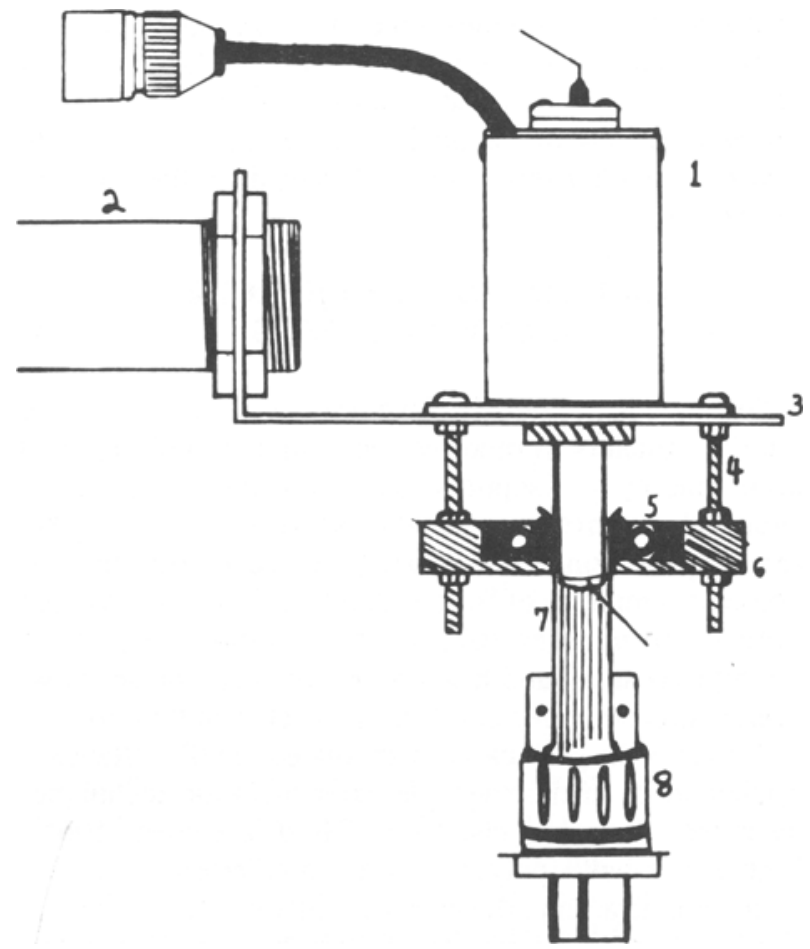

Figure 2. Cutaway diagram of the swivel assembly, illustrating construction of ball race and stainless steel support tubing. The components are: (1) electronic and huid swivel (BRS Model CAY-9606); (2) boom assembly; (3) support plate; (4) $0.125 \times 1.5$ in. screws; (5) ball-bearing support race; (6) aluminum ball-bearing housing; (7) stainless steel tubing; and (8) electronic connector (Cannon Model MS3101A145-5S). 
then fastened to the mating end of the Cannon connector, and the connector is clamped to the stainless steel tube. The connector is then mated to its adjacent half in the tether, and the saline line is connected.

The articulated metal boom (Figure 1) is made of a steel pipe (outer diameter, 0.75 in.; inner diameter, $0.50 \mathrm{in}$.) threaded at both ends. To the other end of the boom is brazed the female end of a 0.375 -in.-drive universal joint (Sears Craftsman Model V4435). A 0.375-in.-drive socket is brazed or welded to the center of a $4 \times 4 \times 0.25$ in. steel plate, which is anchored securely to the wall of the enclosure. The male portion of the 0.375 -in.-drive universal joint mates easily with this mounted socket, providing for rapid detachment as necessary. The boom is free to move horizontally and vertically as the animal moves around in the environment, avoiding stress on or sagging of the tether. Two pulleys and a counterbalanced weight are secured to the wall above the boom-mounting plate. A rope from the counterbalance passes through the pulleys and is anchored to the boom at a point at which the entire system is in equilibrium.

The transducer cable and infusion line pass through a wall of the enclosure to an adjacent equipment room containing a polygraph, computer terminal, and infusion pump. Blood pressure is continuously recorded on the polygraph, enabling inspection of the integrity of the pressure catheter. The transduced pressure signal is recorded by a computer on a beat-to-beat basis for averaging predetermined (e.g., minute-to-minute) intervals. The computer analysis program contains automatic editing features (such as minimal acceptable pulse pressure, etc.) to assist daily review of the quality of the signal. Heart rate is also available from automated analysis of the pressure waveform.

\section{CARDIOVASCULAR SURGERY AND MONITORING}

Techniques previously developed for implantation of arterial catheters in other species can be readily applied to the micropig. Aseptic surgical implantation of an arterial catheter involves sedation with ketamine $(15 \mathrm{mg} / \mathrm{kg})$ and acepromazine $(1 \mathrm{mg} / \mathrm{kg})$, followed by anesthetization with a mixture of isofluorane $(0.5 \%-1.5 \%)$, oxygen $(33 \%)$, and nitrogen $(67 \%)$. The femoral artery of the micropig is small and has a relatively weak pulse; however, a slightly larger artery located between the sartorius and gracilis muscles can be cannulated readily. Standard implantation, anchoring, and exteriorization techniques have been described elsewhere (Herd \& Barger, 1964). Figure 3 shows a polygraph tracing of arterial pressure from an iliac artery: the comparability of blood pressure and heart rate to human levels and the expanded pulsepressure characteristic of the iliac artery can be observed.

Blood-pressure monitoring can be initiated within a few days following implantation of the catheter. Habituation to the living environment prior to catheterization can prevent the occurrence of a gradual decrease in blood pres-

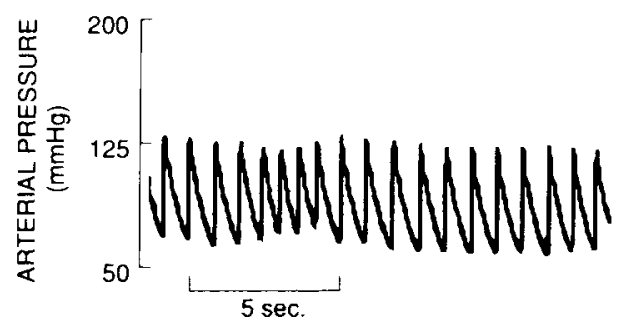

Figure 3. Polygraph tracing of liac arterial pressure in the micropig.

sure while the pig adapts to the situation. Figure 4 shows diurnal variations in systolic and diastolic pressure and heart rate for each of two well-adapted subjects averaged over the last 14 days of 30-day monitoring intervals. Both records show that systolic and diastolic pressure were higher during the nighttime hours than during the daytime hours. For both pigs, heart-rate levels during the daytime period were significantly elevated above the levels maintained at night. Room light onset was at $0600 \mathrm{~h}$, and offset was at $2200 \mathrm{~h}$. The pigs were fed at $1000 \mathrm{~h}$. On the weekends when there were fewer people in the building, the daytime tachycardia and fall in pressure were less marked. In the absence of the daytime tachycardia, daytime and nighttime pressure levels were comparable.

\section{DISCUSSION}

Micropigs tolerate the vest well, and few problems have been encountered with subject-inflicted damage to the monitoring apparatus. Although they may be initially resistant to handling by experimenters, pigs can be trained to stand or lie quietly during application or removal of the vest, servicing of the monitoring apparatus, or recording of rectal temperature. Core temperatures of catheterized pigs have varied between $100.5^{\circ}$ and $102.5^{\circ} \mathrm{C}$, and no infections requiring discontinuation of monitoring have been encountered with the first four animals catheterized.

The diurnal variation observed in the micropig appears to be different from that reported for other species. Like humans (Parati et al., 1990), rats (Smith et al., 1987), dogs (Anderson, Talan, \& Engel, 1990), and monkeys (Engel \& Talan, 1987) typically maintain higher bloodpressure levels during their active periods than during sleep because of higher levels of cardiac output. The daytime decrease in blood pressure in the micropig accompanying sustained tachycardia is consistent with the possibility that sympathetic vasodilator activity is especially prominent in this species. This unique diurnal variation in blood pressure is of interest in light of the tendency for micropigs to develop experimental hypertension.

Micropigs are considered mature at 6 months. Both animals in this report weighed about $35 \mathrm{lb}$ at entry and gained weight in our laboratory at a rate of less than $2 \mathrm{lb}$ per month on a maintenance feeding schedule of $500 \mathrm{~g}$ of chow per day (Charles River Co.). Micropigs were 

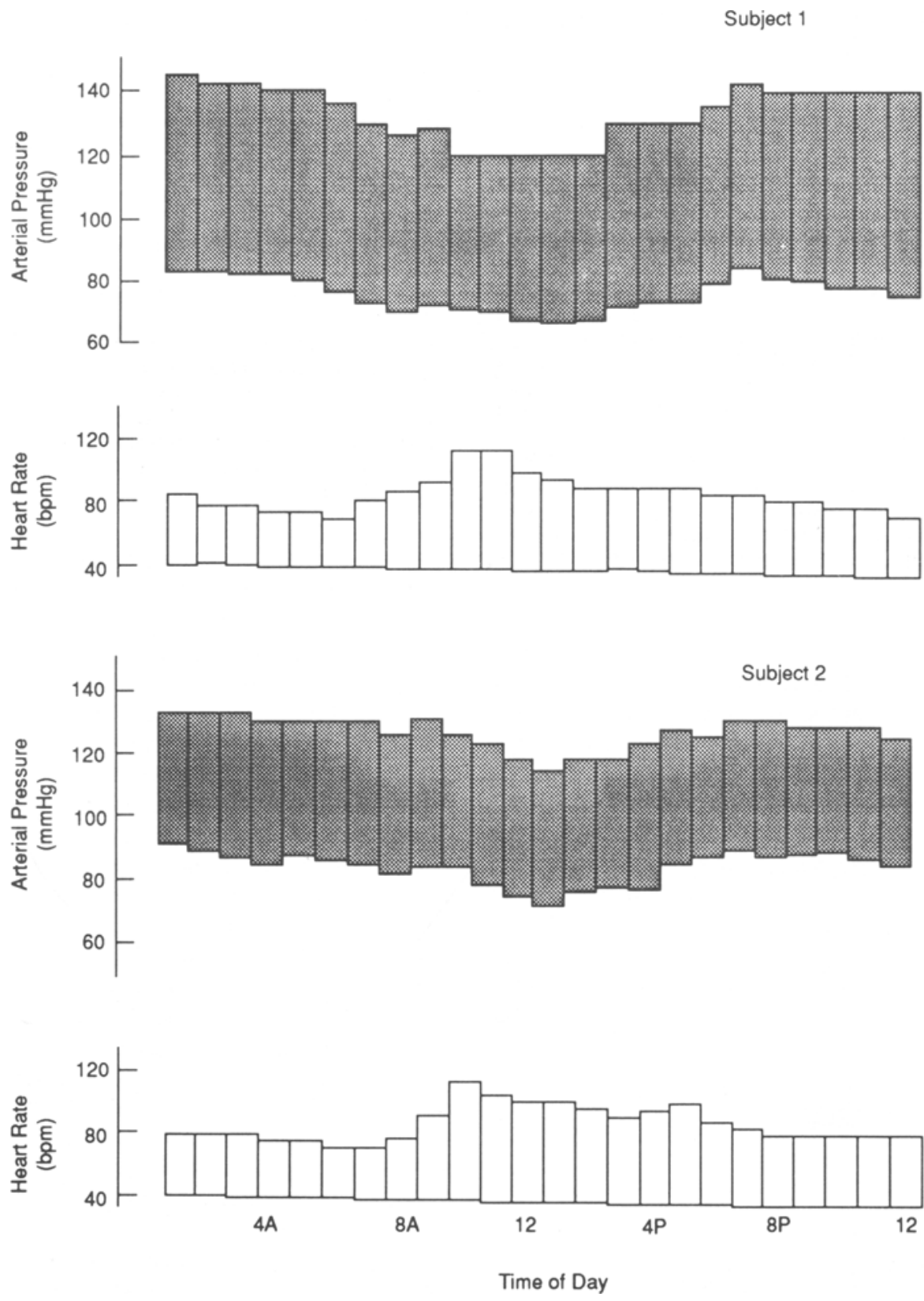

Figure 4. Successive hourly mean levels of systolic and diastolic pressure and heart rate during 24-b monitoring of each of 2 tethered micropigs, averaged over 14 consecutive days.

stably maintained in the laboratory setting with or without visual access to other animals, but their prosocial instincts were evidenced by a transient elevation in arterial pressure when another micropig was removed from an adjoining enclosure. Pigs are relatively neat and will tend to confine eliminated material to one corner of an enclosure. The rooting instinct is apparently satisfied by the addition of animal bedding to the floor. No aggressive behavior toward humans has been encountered to date.

The tether system is not limited to studies of cardiovascular activity but could be applied to a variety of elec- trophysiological measurements. Implanted leads could be passed subdermally to exit sites beneath the vest, with the only constraint being the number of electrical contacts in the swivel. Acute and chronic monitoring also could be performed since the micropig can be trained to lie quietly while the tether is attached to or detached from the vest. In summary, direct monitoring of arterial pressure in the micropig is readily accomplished with procedures that enable intensive observation of multiple variables under highly controlled experimental conditions. The technology offers the prospect of improved understanding of 
interactions of dietary and nondietary behavioral factors in long-term blood-pressure regulation.

\section{REFERENCES}

Anderson, D. E., Talan, M. I., \& Engel, B. T. (1990). Nocturnal hemodynamic patterns in dogs. Physiology \& Behavior, 48, 485-487.

BARNeTt, J. L., \& Hemsworth, P. H. (1986). The impact of handling and environmental factors on the stress response and its consequences in swine. Laboratory Animal Science, 36, 366-369.

Cimini, C. M., \& Zambraski, E. J. (1985). Non-invasive blood pressure measurement in Yucatan miniature swine using tail cuff sphygmomanometry. Laboratory Animal Science, 35, 412-416.

Corbett, W. T., Kuller, L. H., Blaine, E. H., \& Damico, F. J. (1979). Utilization of swine to study the risk factor of an elevated salt diet on blood pressure. American Journal of Clinical Nutrition, 32, 2068-2075.

ENGEL, B. T., TALAN, M. I. (1987). Diurnal pattern of hemodynamic performance in nonhuman primates. American Journal of Physiology: Regulatory, Integrative, \& Comparative Physiology, 253, R779-R785.

HerD, J. A., \& BARGER, A. C. (1964). Simplified technique for chronic catheterization of blood vessels. Joumal of Applied Physiology, 19, 971-972.
Hughes, H. C. (1986). Swine in cardiovascular research. Laboratory Animal Science, 36, 348-350.

Kearns, W. D., Better, W. E., Daley, L. A., \& Anderson, D. E. (1981). A tether system for psychophysiological studies in the dog. Behavior Research Methods \& Instrumentation, 13, 323-327.

Mrtchell, J., \& BoHR, D. F. (1984). Experimental hypertension in the pig. In W. de Jong (Ed.), Handbook of hypertension: Vol. 4. Experimental and genetic models of hypertension (pp. 147-174). Amsterdam: Elsevier.

Parati, G., Mutti, E., Ravogli, A., Trazzi, S., Villani, A., \& ManCIA, G. (1990). Advantages and disadvantages of non-invasive ambulatory blood pressure monitoring. Journal of Hypertension, 8(Suppl. 6), S33-S38.

Smith, G. S., Smith, M. L., \& Mameesh, M. S. (1964). Hypertension and cardiovascular abnormalities in starved-refed swine. Journal of Nutrition, 482, 173-183.

Smith, T. L., Coleman, T. G., Stanek, K. A. S., \& Murphy, W. R. (1987). Hemodynamic monitoring for 24 hours in unanesthetized rats. American Journal of Physiology: Heart \& Circulatory Physiology, 22, 1335-1341.

(Manuscript received March 19, 1991; revision accepted for publication November 7,1991 .) 